\title{
FORMULATION AND IN-VITRO-IN-VIVO EVALUATION OF ALGINATE-CHITOSAN MICROSPHERES OF GLIPIZIDE BY IONIC GELATION METHOD
}

\author{
MAYA SHARMA*, CHOUDHURY PK, SURESH KUMAR DEV \\ Department of Pharmaceutical Sciences, Mohanlal Sukhadia University, Udaipur - 313 001, Rajasthan, India. \\ Email: maya.sharma1703@gmail.com
}

Received: 27 March 2017, Revised and Accepted: 24 April 2017

\section{ABSTRACT}

Objective: This work is aimed to formulate and evaluate alginate-chitosan microspheres of glipizide for the effective use in the treatment of diabetes.

Methods: Sustained release (SR) microspheres were prepared by gentle mixing of polymers in water with the drug by agitation. The polymers used were sodium alginate and chitosan, which was extruded into $5 \%$ calcium chloride solution to produce microspheres by ionic gelation method.

Results: Single unit dosage form of glipizide causes gastric irritation. When converted into the multiple unit dosage forms, it will release the drug evenly throughout the stomach causing suppression of irritation. The aim of the study was to formulate and evaluate alginate-chitosan microspheres, for SR of the chosen drug. The particle size of microspheres was in the range of $200-500 \mu$, maximum mucoadhesive property observed was $88.2 \pm 0.50 \%$ for formulation GCS7, maximum swelling index was $27.0 \%$ for GCS7, and the maximum entrapment was $89.1 \pm 0.28 \%$ for GCS6 formulation. It showed better in-vitro release between $80 \%$ and $90 \%$ for GCS1 and GCS2 formulation and in formulation GCS3, 50-60\% reduction in plasma glucose level than conventional dosage forms when tested in-vivo. The work also aims to study various parameters affecting the behavior of microspheres in oral dosage form.

Conclusion: Drugs with short half life that are absorbed from the gastrointestinal tract (GIT) are eliminated rapidly from the blood flow. To avoid this, the oral SR was developed as this formulation released the drug slowly into the GIT and maintained a stable drug concentration in the serum for a longer duration of time.

Keywords: Glipizide, Sodium alginate, Chitosan, Sustained release microspheres, Scanning electron microscopy, Differential scanning calorimetry, In-vitro and in-vivo activity.

(C) 2017 The Authors. Published by Innovare Academic Sciences Pvt Ltd. This is an open access article under the CC BY license (http://creativecommons. org/licenses/by/4. 0/) DOI: http://dx.doi.org/10.22159/ajpcr.2017.v10i7.18725

\section{INTRODUCTION}

The drug delivery systems that can precisely control the release rates or target drugs to specific body site have an enormous impact on the health-care system. The past two decades have witnessed an avantgarde interaction among the field of polymer and material science, resulting in the development of novel drug delivery systems [1]. Microspheres acquire important features among the particulate drug delivery systems by virtue of their small size and efficient carrier characteristics. However, the success of microspheres delivery system is less due to their short residence time at the site of absorption [2]. The physicochemical characteristics of the active chosen vary considerably, so microspheres are often developed according to specific clinical needs [3]. Microspheres were prepared by the emulsion-gelation method for their ease and cost-effectiveness [4].

Diabetes mellitus (DM) is a chronic metabolic disorder affecting people worldwide, with significant morbidity and mortality caused by its microvascular and macrovascular complications, affecting various vital organs and structures in humans [5]. It has been estimated that by the year 2030, the diabetic population will rapidly increase. However, prevalence is much more, as many patients are asymptomatic and go undiagnosed. Glipizide is an antidiabetic drug used to treat Type II DM. Glipizide with a half life of 2-3 hrs was converted in sustained release (SR) formulation to reduce dosing frequency. A model dosage form is one, which attains the desired therapeutic concentration of drug in plasma and maintains it for the entire duration of treatment. The absorption of glipizide is reduced, when taken after meals hence are advised to be taken on an empty stomach. The sustain release formulations of this drug results in constant plasma level for up to
$24 \mathrm{hrs}$ [6]. It is extensively metabolized $(90 \%)$ by the liver and only $10 \%$ excreted unchanged by the kidney [7].

\section{Glipizide}

Glipizide is an oral blood glucose-lowering drug of the sulfonylurea class, chemical name is l-cyclohexyl-3-[[p-[2-(5-methyrpyrazine-carboxamido) ethyl]phenyl] sulfonyl]urea [8]. It is a whitish, odorless powder, insoluble in water and alcohols, but soluble in $0.1 \mathrm{~N} \mathrm{NaOH}$, and freely soluble in dimethylformamide. Its molecular formula is $\mathrm{C}_{21} \mathrm{H}_{27} \mathrm{~N}_{5} \mathrm{O}_{4} \mathrm{~S}$, the molecular weight is 445.55 , the melting point is $195-200^{\circ} \mathrm{C}$ and pKa is 5.9 [9]. The chemical structure of glipizide shown in Fig. 1.

In this investigation, a formulation of glipizide, capable of providing detectable blood levels over $10 \mathrm{hrs}$ was formulated using expandable, gelling, and swellable hydrocolloid polymer. The polymer used was sodium alginate, which is an inexpensive, nontoxic product extracted from kelp of brown algae. Alginic acid, also called algin or alginate, is an anionic polysaccharide distributed widely in the cell walls of brown algae, which on binding with water forms a viscous gum. It is capable of absorbing 200-300 times of water. Alginates refined from different species of brown seaweed have variations in their chemical structure, resulting in different physical properties. Some may yield an alginate that gives a strong gel, some a weaker gel; some may readily give a cream/white alginate, while some with difficulty and is best used for applications where color does not matter. Sodium alginate has been used as a thickening and gelling agent and because it reduces interfacial tension between an oil and water phase, it is used for the preparation of emulsion also. Alginate is a linear copolymer composed of two monomeric units, D-mannuronic acid, and L-guluronic acid. These monomers occur in the alginate molecule as regions made 
up exclusively of one unit or the other, referred to as M-blocks or G-blocks, or as regions in which the monomers forms an alternating sequence. The calcium reactivity of alginates is a consequence of the particular molecular geometries of each of these regions [10]. Sodium alginate is capable of forming rigid gels by the action of calcium ion or multivalent cations. It is relatively easy to describe alginates in terms of $\mathrm{M}$ and $\mathrm{G}$ units, but the detailed molecular compositions of alginates in terms of block lengths and block distributions are quite difficult to determine [11].

The chitosan entrapped calcium pectinate microspheres have been used for SR of drugs or for targeting drugs to the colon [12].

\section{METHODS}

Glipizide was obtained as a gift sample from by Kreative Organics, Hyderabad. Chitosan from Kerala State chitosan plant, Kerela, and sodium alginate was purchased from $\mathrm{CDH}$, New Delhi. All other chemicals used were of analytical grade.

\section{Preparation of microspheres}

\section{Glipizide chitosan-alginate microspheres}

The required quantity of sodium alginate was dissolved in distilled water $(30 \mathrm{ml})$. Calculated quantity of the drug was added and homogenized. Chitosan in required proportion was dissolved in $2 \% \mathrm{v} / \mathrm{v}$ acetic acid with $\mathrm{pH}(5.5)$ adjusted with $10 \% \mathrm{NaOH}$ solution. $5 \%$ calcium chloride dehydrate solution was added to it. Drug alginate mixture was added to the chitosan-calcium chloride solution dropwise at a constant rate of $30 \mathrm{ml} / \mathrm{h}$ with gentle stirring over thermal controlled magnetic stirrer. The formed microspheres were filtered, washed with acetone and dried in an oven at $35^{\circ} \mathrm{C}$. The dried formulations were stored in an amber colored bottle and kept in a desiccator until used (Table 1).

\section{Percentage yield}

The percentage yield of the microspheres was calculated for each batch by dividing the weight of microspheres by the total weight of drug and polymer.

Percentage yield=Practical yield/theoretical yield $\times 100$

Size distribution and size analysis

Glipizide chitosan microspheres were separated into different size fractions by sieving for 10 minutes using a mechanical shaker containing standard sieves as per Indian Pharmacopeia specifications. The particle size distribution was determined and means particle size of gel beads was calculated by the following formula and shown in Fig. 2.

Mean particle size $=\frac{\sum\left(\begin{array}{l}\text { Mean particle size of the fraction } \\ \times \text { weight fraction }\end{array}\right)}{\Sigma(\text { Weight fraction })}$

Table 1: Formulation process codes and parameter for the formulation of the glipizide microspheres by ionic gelation method

\begin{tabular}{lllllll}
\hline \multicolumn{7}{l}{ Alginate-chitosan microspheres } \\
\hline Code Drug & $\begin{array}{l}\text { Sod. } \\
\text { alginate }\end{array}$ & Chitosan & $\begin{array}{l}\text { Distilled } \\
\text { water }\end{array}$ & CaCl $_{2}$ (5\%) & D:P \\
\hline GCS1 & $100 \mathrm{mg}$ & + & + & $30 \mathrm{ml}$ & $100 \mathrm{ml}$ & $1: 0.5$ \\
GCS2 + & + & + & + & + & $1: 1$ \\
GCS3 + & + & + & + & + & $1: 1.2$ \\
GCS4 + & + & + & + & + & $1: 1.4$ \\
GCS5 + & + & + & + & + & $1: 1.6$ \\
GCS6 + & + & + & + & + & $1: 1.8$ \\
GCS7 + & + & + & + & + & $1: 2$ \\
\hline
\end{tabular}

D:P: Drug to polymer ratio, +: Present
Differential scanning calorimetry (DSC)

Thermograms of drug, polymers, and microspheres were obtained using DSC 822e (Mettler Toledo) calorimeter. DSC measures the amount of heat energy absorbed or released by a sample, as it is heated, cooled or held at a constant temperature. Thermogram shows that no interaction seen between polymers and also between the polymer and drug. The drugs and polymers showed separate peaks in thermogram (Fig. 3).

\section{Scanning electron microscopy (SEM)}

The samples for the SEM analysis were prepared by sprinkling the microspheres on one side of the double adhesive stub. The stub was then coated with fine gold dust. The microspheres were then observed under the SEM (JEOL Model JSM-6390LV) at $15 \mathrm{kV}$. It showed discreet, more and less uniform and uniformly distributed microspheres (Fig. 4).

\section{Entrapment efficiency}

The prepared microspheres were dissolved, and the amount of drug present in weighed samples was determined by analyzing spectrophotometrically at $276 \mathrm{~nm}$ after filtration and suitable dilutions [13]. The method obeyed Beer's law in the concentration range of $0-35 \mu \mathrm{g} / \mathrm{ml}$. The entrapment efficiency was calculated from the theoretical amount and actual amount of the drug in dry microspheres.

Drug entrapment efficiency (\%)=Calculated drug content/theoretical drug content $\times 100$

\section{Swelling index}

Swelling index was determined by measuring the extent of swelling of microspheres in a particular buffer solution. To ensure complete equilibrium weighed, the amount of microspheres was allowed to swell in a buffer solution. The excess liquid adhering to the drops were removed by blotting, and the swollen microspheres were weighed using microbalance. The hydrogel microspheres were then dried in an oven at $60^{\circ} \mathrm{C}$ for $5 \mathrm{hrs}$ until there was no change in the dried mass of the sample. The swelling index of the microsphere was calculated by the following formula [14].

\section{$\underline{\text { Mass of swollen microspheres - Mass of dry microspheres }} \times 100$} Mass of dried microspheres

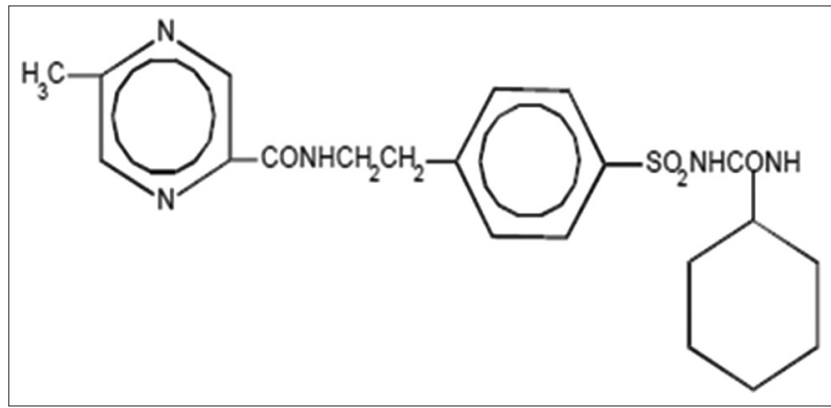

Fig. 1: Chemical structure of glipizide

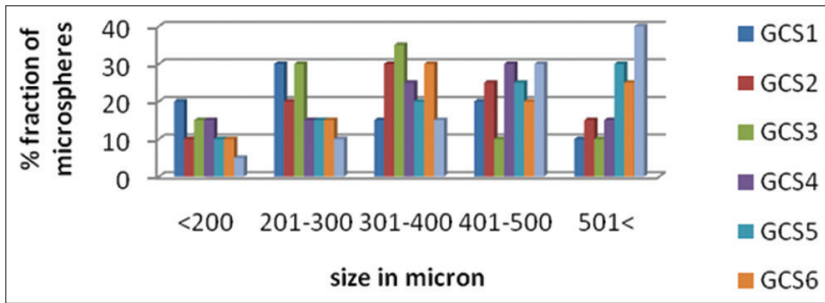

Fig. 2: Size distribution of sodium alginate microspheres of drug glipizide (Drug to polymer-1: 0.5-1:2) 


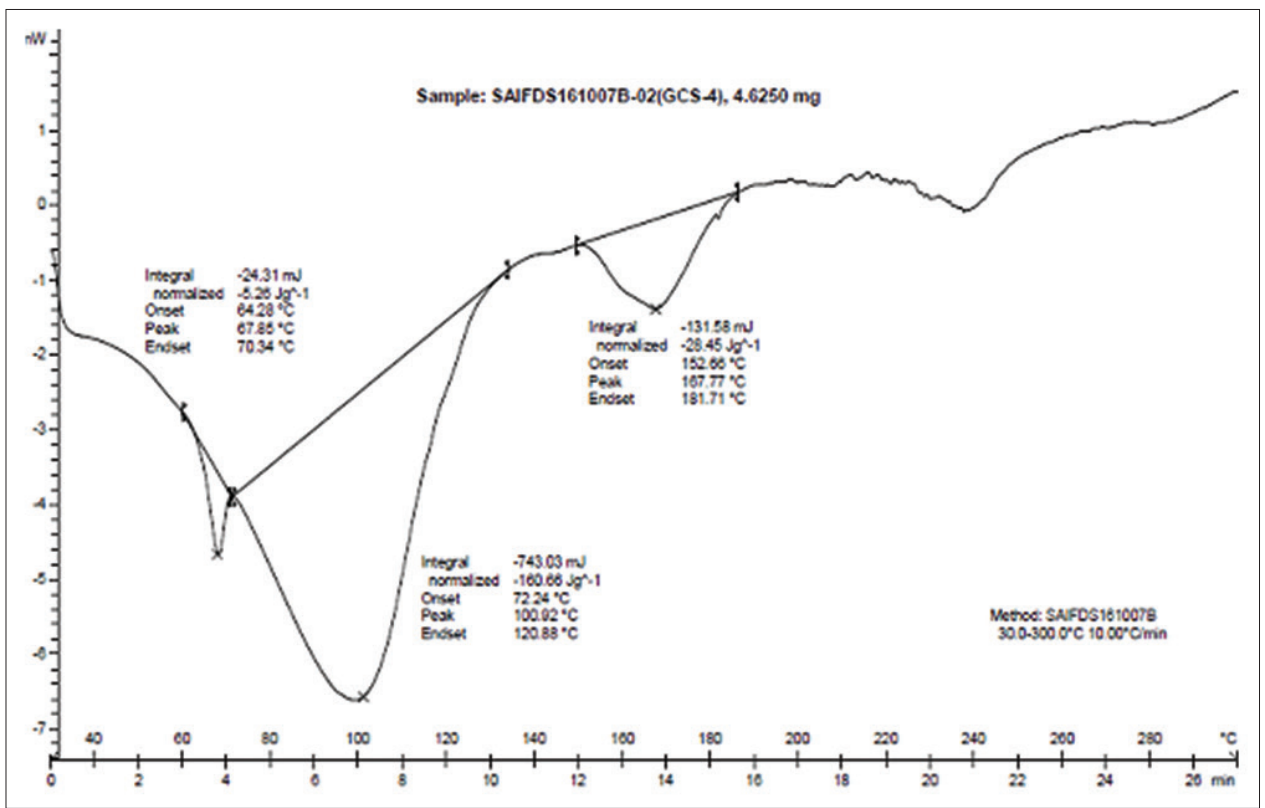

Fig. 3: Differential scanning calorimetry of glipizide alginate-chitosan microspheres (GCS-4)

Mucoadhesive studies

Approximately 50 microspheres were taken and spread uniformly over a wet glass slide, which was held to the walls of the beaker with glue. This assembly was then introduced into the USP disintegration apparatus. A number of microspheres still adhering to the glass slide was counted at regular intervals and assessed for the mucoadhesive nature of the microspheres. All the readings were taken in triplicate and results depicted in \pm standard deviation (SD) (Table 2).

\section{In-vitro release studies}

Preparation of standard plot in methanol

Glipizide $(50 \mathrm{mg}$ ) was dissolved in $100 \mathrm{ml}$ of methanol. It was then suitably diluted for graded solutions in a range of $0-35 \mu \mathrm{g} / \mathrm{ml}$. The absorbance was read using an ultraviolet (UV) spectrophotometer (Shimadzu 1800) at $\lambda_{\max } 276 \mathrm{~nm}$ (Table 3 and Fig. 5).

\section{In-vitro release of microspheres}

The in-vitro release studies were conducted at $37 \pm 0.5^{\circ} \mathrm{C}$ and at $100 \mathrm{rpm}$ by buffer change method using $0.1 \mathrm{~N} \mathrm{HCl}(1 \mathrm{hrs}), 4 \mathrm{pH}(1 \mathrm{hrs}), 6 \mathrm{pH}$ ( $3 \mathrm{hrs}), 6.8 \mathrm{pH}(3 \mathrm{hrs})$, and $7.4 \mathrm{pH}(2 \mathrm{hrs})$ phosphate buffers $(200 \mathrm{ml})$ in sink conditions using a diffusion cell. Accurately weighed sample of prepared microspheres was added to the donor cell. At preset time intervals; $5 \mathrm{ml}$ of aliquots were withdrawn and replaced by an equal volume of fresh dissolution medium. The aliquots were analyzed UV spectrophotometrically at $\lambda_{\max } 276 \mathrm{~nm}$ after proper dilution (Table 4 and Fig. 6).

\section{In-vivo hypoglycemic activity}

In-vivo hypoglycemic activity of Glipizide formulation, in normal and hyperglycemic rats

The in-vivo hypoglycemic activity was conducted in healthy and hyperglycemia-induced male albino Wistar rats of $175 \pm 25$ g body weight by measuring the hyperglycemic effect produced after oral administration of a microspheres dose equivalent to $5 \mathrm{mg} / \mathrm{kg}$ body weight of glipizide in comparison to the pure drug at the same dose.

All animal experiments were approved by Institutional Animal Ethics Committee (IAEC) of Pinnacle Biomedical Research Institute (PBRI) Bhopal (Reg. No. 1824/PO/ERe/S/15/CPCSEA). Protocol Approval Reference No. PBRI/IAEC/PN-16042. Animals were housed in separate cages under controlled conditions of temperature $\left(22 \pm 2^{\circ} \mathrm{C}\right)$. All animals were given standard diet (golden feed, New Delhi) and water regularly [15].

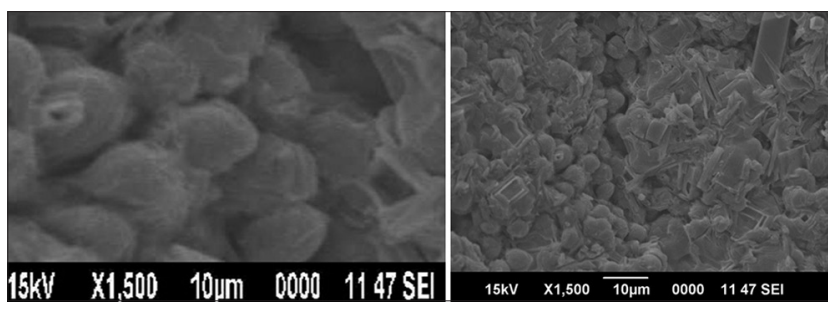

Fig. 4: Scanning electron microscopy of GCS-7

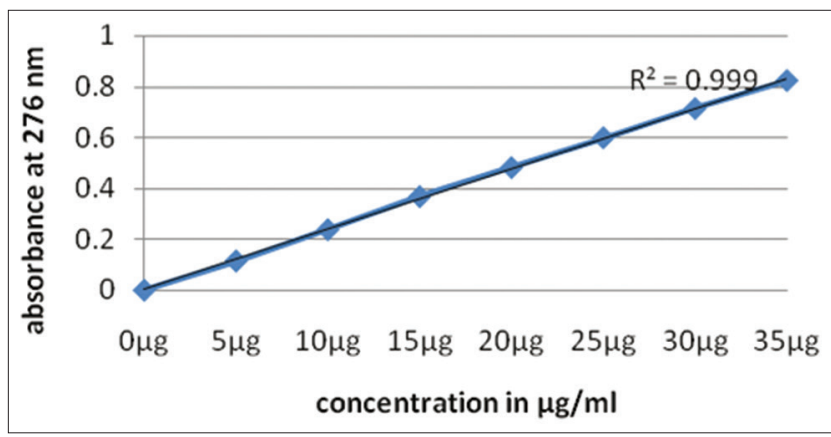

Fig. 5: Standard plot of glipizide in methanol

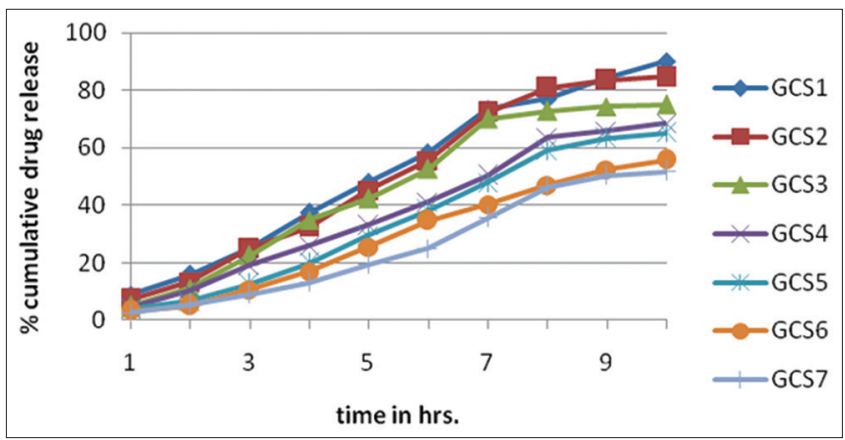

Fig. 6: In-vitro drug release of GCS1-GCS7

Animals were kept at $12 \mathrm{hrs}$ in alternating light and dark cycles. Animals were further divided into eight groups with six animals in each group (Table 5) [16]. 
Table 2: Physicochemical properties of the glipizide chitosan-alginate microspheres (D:P-1: 0.5-1:2), n=3

\begin{tabular}{|c|c|c|c|c|c|c|}
\hline \multicolumn{7}{|c|}{ Chitosan-alginate microspheres of glipizide } \\
\hline Code & $\%$ yield & $\%$ entrapment \pm SD & Shape & Color & $\%$ Swelling index & Mucoadhe. property $(\%) \pm S D$ \\
\hline GCS1 & 90.6 & $87.1 \pm 0.10$ & Spherical & Light brown & 11.5 & $49.1 \pm 0.60$ \\
\hline GCS2 & 85.2 & $84.4 \pm 0.15$ & Spherical & Light brown & 15.7 & $63.0 \pm 1.50$ \\
\hline GCS3 & 84.3 & $89.6 \pm 0.10$ & Spherical & Light brown & 17.2 & $65.2 \pm 1.14$ \\
\hline GCS4 & 92.0 & $88.4 \pm 0.10$ & Spherical & Light brown & 19.0 & $69.5 \pm 1.52$ \\
\hline GCS5 & 91.1 & $72.1 \pm 0.07$ & Spherical & Light brown & 20.5 & $72.5 \pm 0.45$ \\
\hline GCS6 & 85.1 & $89.1 \pm 0.28$ & Spherical & Light brown & 24.5 & $81.3 \pm 0.43$ \\
\hline GCS7 & 83.3 & $82.0 \pm 0.10$ & Spherical & Light brown & 27.0 & $88.2 \pm 0.50$ \\
\hline
\end{tabular}

SD: Standard deviation

Table 3: Glipizide pure drug absorbance in UV spectrophotometer

\begin{tabular}{lll}
\hline S.No. & Concentration $(\boldsymbol{\mu g} / \mathbf{m l})$ & Absorbance at $(\mathbf{2 7 6} \mathbf{~ n m})$ \\
\hline 1 & 0 & 0 \\
2 & 5 & 0.115 \\
3 & 10 & 0.238 \\
4 & 15 & 0.368 \\
5 & 20 & 0.482 \\
6 & 25 & 0.599 \\
7 & 30 & 0.714 \\
8 & 35 & 0.824 \\
\hline
\end{tabular}

UV: Ultraviolet

\section{Induction of diabetes}

1. Diabetes was induced in rats by intraperitoneal injection of streptozotocin (STZ) at a dose of $60 \mathrm{mg} / \mathrm{kg}$ body weight. STZ dissolved in ice cold $0.1 \mathrm{M}$ citrate buffer

2. The animals were allowed to drink $5 \%$ glucose solution overnight to overcome STZ induced hyperglycemia

3. The animals were considered as diabetic, if their blood glucose value was above $200 \mathrm{mg} / \mathrm{dl}$ on the $3^{\text {rd }}$ day of STZ injection

4. The treatment was started on the $4^{\text {th }}$ day after the STZ injection, considering it as the $1^{\text {st }}$ day of treatment. The treatment was continued till 7 days

5. Blood glucose level and body weight were observed on $0,3,5$, and $7^{\text {th }}$ day of post-treatment (Table 6).

\section{Experimentation}

All animals were divided randomly into six groups with six animals in each group. Group I, received normal saline orally only and served as vehicle control, Groups II, III, IV, V, VI, and VII were made diabetic with STZ. Group II received saline, Groups III and IV received glipizide $(5 \mathrm{mg} / \mathrm{kg}$ ) per day oral, Groups V, VI, and VII received formulation GCS3 (5 mg/kg) per day oral. All dosing of test samples was done orally throughout the experimentation (Table 7 and Fig. 7).

\section{Stability studies of formulations}

Stability testing is an integral part of the formulation development. It generates information about the shelf life of drug substances and their formulations and recommends appropriate guidelines for storage $[17,18]$. In the formulations GCS1-GCS7, there was no significant change in stability. Loss of drug content was seen in formulations with low polymer concentrations.

\section{Morphological characteristics and release profile}

The formulated microspheres were stable throughout the course of study of about ( 90 days) at $5^{\circ} \mathrm{C}$ in the freezer, at room temperature $\left(32^{\circ} \mathrm{C}\right)$ and at $45^{\circ} \mathrm{C}$ in oven $[19,20]$. There was no significant morphological change or changes in release characteristics. Slight color changes were observed at elevated temperature because of degradation of polymers.

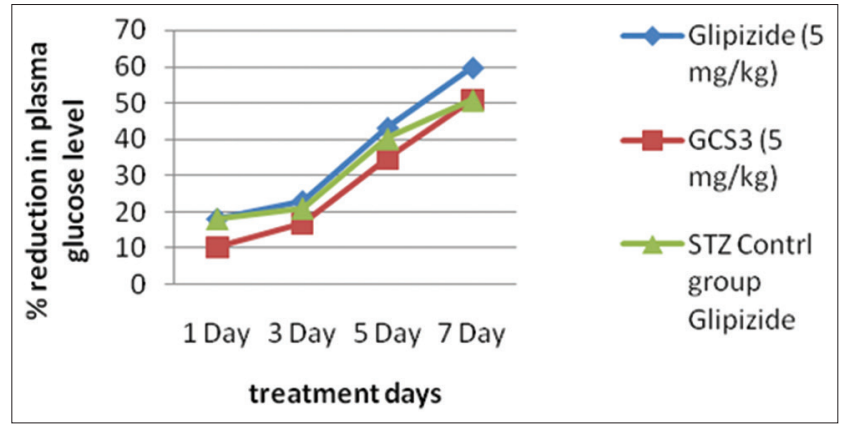

Fig. 7: \% reduction in plasma glucose level in hyperglycemic rats after administration of pure drug and formulation GCS3

\section{RESULT AND DISCUSSION}

The effects of process variables on various physicochemical, morphological and in-vitro release characteristics were studied. The low coefficient of variations showed that the method is highly reproducible.

Microspheres of glipizide were formulated using sodium alginate and chitosan by orifice ionic gelation method. Different concentrations of the polymer were used to entrap the drug, and various process variable parameters were analyzed.

The microspheres were discrete, free flowing and monolithic matrix type. A coat of chitosan was also produced on the surface of the alginate microparticles.

The mucoadhesive property of the microspheres increased with increase in the concentration of polymer. The size distribution was in the range of 200-500 $\mu \mathrm{m}$. It was observed that increase in the polymer ratio, increased the size of the microspheres. Incorporation of more polymers resulted in increased size due to the distribution of the insoluble drugs in the interstitial spaces of the matrix.

It was observed that higher proportion of polymer in the formulation resulted in the microspheres being smoother. The drug release rate decreased with increase in chitosan concentration. Microspheres showed the inherent brown color of the polymers. When the proportion of polymer was increased, the percentage yield and the drug entrapment also improved.

Drug release characteristics were studied in simulated gastric and intestinal fluid without pepsin to simulate the gastrointestinal environment. Release was slow and uniformly spread over a period of time. This could be attributed to the matrix nature of the formulation. Poor water soluble drugs seem to rush initially into the interstitial spaces of the polymer, from where the water phase forces the drug into the gel portion of the polymer. The swelling hydrophilic membrane then acts as a flux controlling barrier $[21,22]$. Thus, alginate microspheres with chitosan, prepared by simple ionic gelation method, could be used for sustain release of the drug [23]. The drug release was diffusion as well as erosion controlled. 
Table 4: In-vitro release kinetic equation data of glipizide chitosan-alginate microspheres (D:P-1: 0.5-1:2), $n=3$ for values

\begin{tabular}{|c|c|c|c|c|c|}
\hline \multirow[t]{2}{*}{ Code } & Zero order & First order & Higuchi & Korsmeyer-Peppas & Hixson-Crowell \\
\hline & $\mathbf{R}_{0}$ & $\mathbf{R}_{1}$ & $\mathbf{R}_{\mathbf{H}}$ & $\mathbf{R}_{\mathrm{K}}$ & $\mathbf{R}_{\mathrm{HC}}$ \\
\hline GCS1 & 0.987 & 0.955 & 0.985 & 0.744 & 0.982 \\
\hline GCS3 & 0.979 & 0.958 & 0.976 & 0.774 & 0.962 \\
\hline GCS4 & 0.980 & 0.968 & 0.981 & 0.814 & 0.978 \\
\hline GCS5 & 0.976 & 0.966 & 0.976 & 0.842 & 0.974 \\
\hline GCS6 & 0.981 & 0.983 & 0.980 & 0.873 & 0.986 \\
\hline GCS7 & 0.982 & 0.974 & 0.980 & 0.901 & 0.955 \\
\hline
\end{tabular}

R: Regression coefficient value, D:P: Drug to polymer ratio

Table 5: For in-vivo grouping of animals

\begin{tabular}{lll}
\hline Group No. & Treatment & Dose \\
\hline 1 & Normal saline & Number of animals \\
2 & STZ (STZ control) & $5 \mathrm{ml} / \mathrm{kg} \mathrm{p.o.}$ \\
3 & Glipizide & $60 \mathrm{mg} / \mathrm{kg} \mathrm{i.p.}$ \\
4 & GCS3 & $5 \mathrm{mg} / \mathrm{kg} \mathrm{p.o.}$ \\
\hline
\end{tabular}

STZ: Streptozotocin

Table 6: Blood glucose level (mg/dl)

\begin{tabular}{lllll}
\hline S.No. & Treatment & 0 Day & 3 Day & 5 Day \\
\hline 1 & Normal saline $(5 \mathrm{ml} / \mathrm{kg})$ & $87.90 \pm 5.626$ & $89.60 \pm 5.873$ & $90.48 \pm 6.485$ \\
2 & STZ control & $284.35 \pm 11.734$ & $289.43 \pm 12.438$ & $293.92 \pm 12.020$ \\
3 & Glipizide $(5 \mathrm{mg} / \mathrm{kg})$ & $282.93 \pm 8.574$ & $222.65 \pm 8.025^{*}$ & $166.90 \pm 8.773^{*}$ \\
4 & GCS3 $(5 \mathrm{mg} / \mathrm{kg})$ & $287.37 \pm 4.623$ & $240.72 \pm 5.101^{*}$ & $119.43 \pm 9.211^{*}$ \\
\hline
\end{tabular}

Values are expressed as mean \pm SD at $\mathrm{n}=6$. One-way ANNOVA followed by Bonferroni test, ${ }^{*} \mathrm{p}<0.050$ significant compared to the diabetic control group.

STZ: Streptozotocin, SD: Standard deviation

Table 7: Reduction in plasma glucose levels after administration of pure drug and glipizide formulation in rats

\begin{tabular}{lllll}
\hline Treatment & 1 day & 3 day & $\mathbf{5}$ day & $\mathbf{7}$ day \\
\hline STZ control group glipizide & 18.101 & 21.013 & 40.211 & 50.874 \\
Glipizide (5 mg/kg) & 18.213 & 23.072 & 43.215 & 59.751 \\
GCS3 (5 mg/kg) & 10.351 & 16.829 & 34.597 & 50.898 \\
\hline
\end{tabular}

STZ: Streptozotocin

\section{Statistical analysis of in-vivo data}

All data were analyzed by one-way ANOVA followed by Bonferroni test. $\mathrm{p}<0.05$ was considered as the level of significance. All data are presented in mean \pm SD.

Glipizide showed a significant decrease in plasma glucose levels in both normal and hyperglycemic rats.

A $25 \%$ reduction in glucose is considered a significant hypoglycemic effect. The sustained hypoglycemic effect with microspheres is due to the slow release and absorption of glipizide over extended periods of time.

The plasma glucose level of diabetic controlled rats increased significantly from day 3 to day 7 of STZ injection. Hyperglycemic rats were selected for the study as discussed above. The plasma glucose data obtained indicates that the drug is entrapped in microspheres and produced the consistent antihyperglycemic effect. This effect was pronounced in the case of hyperglycemic rats whereas normal rats showed comparatively lesser alterations in plasma glucose level after formulation administration.

\section{CONCLUSION}

A new SR system of glipizide microspheres of alginate-chitosan was designed and formulated by an ionic gelation method. It's morphological, and release characteristics were studied. The microspheres were easy to prepare, and the mean diameter of microspheres increased with increase in the amount of the polymers increase. The pore size of microspheres was affected by the concentration of the alginate and chitosan. Stirring at high speed above 200 rpm causes the destruction of microspheres. The microspheres showed excellent in-vivo activity and SR characteristics as compared to the conventional oral dosage forms. Thus, drug entrapment technique is a useful tool for the development of multiparticulate system even for a water-insoluble drug.

\section{ACKNOWLEDGMENT}

Authors are grateful to Sophisticated Test and Instrumentation Centre, Cochin University, Kochi, Kerala, for providing DSC and SEM facility and also PBRI, Bhopal, for providing in-vivo facility.

\section{REFERENCES}

1. Mathiowitz E, Chickering D, Jacob JS, Santos C. Bioadhesive drug delivery systems. Encycl Control Drug Deliv 1999;1:9-44.

2. Sharma M, Jain K, Dev SK, Choudhury PK. Formulation and evaluation of sodium alginate beads by emulsion gelation method. Asian J Pharm 2017;11(1):S101-6.

3. Ararath D, Velmurugan S. Formulation and evaluation of nevirapine mucoadhesive microspheres. Int J Pharm Pharm Sci 2015;7:342-8.

4. Hong X, Wei L, Ma L, Chen Y, Liu Z, Yuan W. Novel preparation method for sustained-release PLGA microspheres using waterin-oil-in-hydrophilic-oil-in-water emulsion. Int $\mathrm{J}$ Nanomedicine 2013;8:2433-41.

5. Jorgensen L, Moeller EH, van de Weert M, Nielsen HM, Frokjaer S. Preparing and evaluating delivery systems for proteins. Eur J Pharm Sci 2006;29(3-4):174-82

6. Castellanos IJ, Cruz G, Crespo R, Griebenow K. Encapsulationinduced aggregation and loss in activity of gamma-chymotrypsin and their prevention. J Control Release 2002;81(3):307-19.

7. Ceriello A. The emerging role of post-prandial hyperglycaemic spikes in the pathogenesis of diabetic complications. Diabet Med 1998;15(3):188-93. 
8. Ministry of Health and Family Welfare. Indian Pharmacopoeia. Vol. 4. New Delhi: Controller of Publications, Government of India, Ministry of Health and Family Welfare; 2007. p. 549-50.

9. Goyal S, Rai JK, Narang RK, Rajesh KS. Sulfonyl ureas for antidiabetic therapy, an overview for glipizide - Review article. Int J Pharm Pharm Sci 2010;2 Suppl 2:1-6.

10. Deruiter J. Overview of the Antidiabetic Agents, Endocrine Pharmacotherapy Module Spring, 2003;25:1-33.

11. Mishra P, Singh DN, Purohit S. Box Behnken design in optimization and evaluation of metformin $\mathrm{HCl}$ loaded guar gum microspheres. Invent Rapid NDDS 2012;2012(4):1-8.

12. Choudhury PK, Kar M. Preparation of alginate gel beads containing metformin hydrochloride using emulsion - Gelation method. Trop J Pharm Res 2005;4(2):489-93.

13. Choudhury PK, Kar M, Chauhan CS. Cellulose acetate microspheres as floating depot systems to increase gastric retention of antidiabetic drug: Formulation, characterization and in vitro-in vivo evaluation. Drug Dev Ind Pharm 2008;34(4):349-54.

14. Sarode SM, Mittal M, Magar RM, Shelke AD, Shrivastava B, Vidyasagar G. Formulation and evaluation of floating microspheres of glipizide. J Chem Pharm Res 2011;3(3):775-83.

15. Prisilla DH, Balamurugan R, Shah HR. Antidiabetic activity of methanol extract of Acorus calamus in STZ induced diabetic rats. Asian Pac J Trop Biomed 2012;2(2):S941-6.
16. Rajurkar BM. Phyto-pharmacological investigations of Clerodendrum infortunatum gartns. Int Res J Pharm 2011;2(11):130-2.

17. Phutane P, Shidhaye S, Lotlikar V, Ghule A, Sutar S, Kadam V. In vitro evaluation of novel sustained release microspheres of glipizide prepared by the emulsion solvent diffusion-evaporation method. J Young Pharm 2010;2(1):35-41.

18. Sinha VR, Singla AK, Wadhawan S, Kaushik R, Kumria R, Bansal K, et al. Chitosan microspheres as a potential carrier for drugs. Int J Pharm 2004;274(1-2):1-33

19. Nair R, Haritha B, Reddy CK, Kumar A, Kumar JK. Application of chitosan microspheres as drug carriers: A review. J Pharm Sci Res 2009;1(3):1-12.

20. Longer MA, Cheng HS, Robinson JR. Mucoadesive materials for CR dosage forms. J Pharm Sci 1987;74:406-10.

21. Mesiha M, Sidhom M. Increased oral absorption enhancement of insulin by medium viscosity hydroxyl propylcellulose. Int J Pharm 1995; 115:137-40.

22. Wan LS, Heng PW, Wong LF. Matrix swelling: Simple model describing extent of swelling of HPMC matrices. Int J Pharm 1995;116(2):159-68

23. Menshawe EL, Shahira F, Rasha MK, Doaa SH, Abdelkhalek H. Effect of biodegradable co-polymers and divalent cations on the sustained release ability of propranolol hydrochloride loaded biomaterial microspheres. Int J Pharm Pharm Sci 2016;8:311-7. 